\title{
Two decades of optometric education in Ghana: Update and recent developments*
}

\author{
GO Ovenseri-Ogbomo ${ }^{a}$, FE Kiob ${ }^{b}$, EK Mornyc, AO Amedod and OM Oriowo ${ }^{\mathrm{e}}$ \\ ${ }^{a}$ Department of Optometry, University of Cape Coast, Cape Coast, Ghana \\ ${ }^{b}$ Department of Optometry, University of Benin, Benin City, Nigeria \\ ${ }^{c}$ Morny Eye Center, Kumasi, Ghana \\ ${ }^{d}$ Department of Optometry and Vision Science, Kwame Nkrumah University of Science and Technology, Kumasi, \\ Ghana \\ ${ }^{e}$ Department of Optometry, School of Health Sciences University of Limpopo, Turfloop, South Africa
}

<ovenseriogbomo@yahoo.com>

Received 24 November 2010; revised version accepted 16 August 2011

\begin{abstract}
Many authors have reported on the evolution and trends of optometric education in Africa. Amongst these are articles on Optometry and optometric education in Africa, West Africa, Nigeria, South Africa, Ghana, and Ethiopia. This article reports the historical perspectives of optometric education in Ghana and the developments that have been made in the last 20 years. It also attempts to relate the
\end{abstract}

stride made towards legal recognition of optometry in Ghana. In presenting this historical account, it is hoped that sometime in the future, one should be able to look back at the beginning of optometry training in Ghana and be able to measure the advancement or otherwise that have been made since its inception. (S Afr Optom 2011 70(3) 136-141)

Key words: Optometry, optometric education, University of Cape Coast, Ghana

\section{Introduction}

Several optometric educators have made efforts to document the evolution and trends of optometric education in Africa. Amongst these are Penisten ${ }^{1}$ and Sheni ${ }^{2}$ (Optometry and optometric education in Africa); Sheni ${ }^{3}$ (West Africa); Ogbuehi ${ }^{4}$ (Nigeria); Ferreira $^{5}$, Oduntan ${ }^{6}$ and Mashige ${ }^{7}$ (South Africa); Randall and $\mathrm{Kumah}^{8}$ (emergence of optometric education in Ghana); and Carlson ${ }^{9}$ (Ethiopia).

The need to establish formal training programmes for optometric education in Ghana was first mooted by the late Dr Francis K Morny, a foremost British- trained Ghanaian optometrist. This was occasioned by the failure of a bill that was sent to the Ghanaian parliament for the regulation of the practice of optometry in Ghana in the early 1980s. The main reason for the failure of the bill was that the Ghana Optometric Association that proposed this bill did not have the mandatory membership of 25 for a profession to be regulated. Following the defeat of the bill in the parliament, Mr. Morny (who subsequently became Dr Morny in 1998 after obtaining the Doctor of Optometry (OD) degree from Abia State University, Uturu, Nigeria at the age of 75 years), in 1985 proposed to some Ghanaian universities to start an optometry

${ }^{a} \mathrm{OD} \mathrm{MPH}$

${ }^{b} \mathrm{BSc}$ OD MSc

${ }^{c} \mathrm{BSc}$ OD

${ }^{d}$ BSc PGDip(Optom) OD PhD

${ }^{e} \mathrm{BSc}$ (Optom) MSc PhD FAAO

*An excerpt of this paper was presented at the 6th World Conference on Optometric Education, Durban, South Africa. 
training programme. At the time none of the universities were favorably disposed to the idea of starting a programme in optometry. Thus began the quest for formal university optometric education in Ghana.

\section{Meeting the 25-member mark}

Mr. Morny reported how, in 1987 while reading a copy of Interoptics, he knew how the number of optometrists in Norway was increased by starting an optometry school in the country ${ }^{10}$. Thus, in 1988, he started the now defunct Premier College of Optometry in Kumasi as a private institution. The college trained and awarded certificates to refracting opticians who had acquired their skills as apprentices without any certification. In 1990, the Premier College of Optometry formally admitted five students who had completed their Bachelors of Science Degrees for a one year course in optometry. Faculty for this program was drawn from the biological sciences and physics of the University of Science and Technology (UST), Kumasi (now Kwame Nkrumah University of Science and Technology (KNUST). An Eye hospital located about 50 miles $(80 \mathrm{~km})$ away provided courses in anatomy and ocular pathology ${ }^{10}$. Apparently, the facility also provided clinical training for the students. As the college was not an accredited private institution, Dr. Morny intensified communication in early 1990s with professional associations such as the Nigerian Optometric Association and International Optometry and Optical League (now the World Council of Optometry) requesting assistance with establishing formal university level optometry programme in Ghana.

Between 1990 and 1991, there were regular communication between Mr. Morny and two secretaries of the Nigerian Optometric Association (FEK and OMO based at the University of Benin at the time). Both of them were at different times Secretary of the Nigerian Optometric Association. In 1990, a curriculum development workshop sponsored by the West African College of Surgeons (facilitated by Prof. Majekodunmi at the University of Lagos Teaching Hospital (LUTH) Ophthalmology Department) was held at the University of Benin, Department of Optometry for two days. The workshop was to develop a training curriculum for increasing the much needed middle level primary eye care manpower in rural Africa. Those present at the workshop included a lec- turer from the University of Science and Technology, Ghana; Dr. Hannah Faal (an ophthalmologist), Gambia; Prof. Majekodunmi (an ophthalmologist), Lagos University Teaching Hospital (LUTH), Dr. Kio, Mr. Oriowo (Now, Prof. Oriowo), Dr. Sheni (now Prof. Sheni), University of Benin and Prof. Mencias, The Principal of the Ophthalmic Nursing program at University of Benin Teaching Hospital (UBTH), Nigeria. The recommendation from the workshop was submitted to the Nigerian Health Board office in Lagos in May 1991 for onward transmission to the stakeholders and beneficiaries which included the University of Science and Technology (UST), Kumasi, Ghana.

Subsequently, in mid-1991, the University of Science and Technology (UST) invited Dr. Morny with a view to starting a University based Optometry program sequel to his proposal in 1985 . In 1991, the Optometry program started within the Department of Physics at UST 8,10 now Kwame Nkrumah University of Science and Technology (KNUST) $\}$. Although KNUST offered programs in medicine, pharmacy, community health and medical technology, opposition from certain individuals in the medical school did not allow the establishment of the Optometry programme within the Faculty of Health Sciences ${ }^{1}$. It was subsequently located in the Physics Department. Notwithstanding this opposition, staff members from the medical school gave lectures in anatomy and ocular pathology. The new Optometry program in KNUST was a two-year postgraduate diploma in optometry (PGDip Optom) and applicants to this program already had a Bachelors Degree in Science. The objectives of the Postgraduate Diploma in Optometry at KNUST included ${ }^{11}$ :

To produce optometrists with adequate background in basic sciences and health sciences,

To provide such training as to equip optometrists to render community health care,

To train aspiring optometrists in the field of primary eye care,

To train optometrists with managerial, research and professional skills who can play a leadership role in health care delivery,

To train optometrists with scientific and professional standards, who will be capable of functioning and competing internationally, and;

To provide education, to equip the individual as a respected professional person who is acknowledged as a potential community leader. 
The programme was designed to prepare graduates to engage in basic optometric practice which would include comprehensive eye examination, refraction, ocular disease recognition and referral, and treatment of limited ocular diseases in the interest of the public. In order to be awarded the PGDip (Optom), candidates were required to complete 72 semester hours of lectures, laboratories and clinics 8,11 . In terms of international assistance, Vision Aids Overseas, Rotary Club International, World Vision International and Voluntary Services Overseas of the British Council provided support by providing equipment, used spectacles, books, journals, and by organizing outreach / eye camps with faculty, students, and visiting expatriate optometrists.

\section{Change in the curriculum at KNUST}

It would appear that the motivation to rapidly increase the number of optometrists in Ghana to meet the 25-member mark required for regulation of the profession and the need to provide primary eye care in the country, informed the two-year post graduate diploma program at KNUST. Having produced 45 graduates from this program ${ }^{8}$, there was the need to upgrade the program.

In 2000, a decade after a formal University program in Optometry began at KNUST; the University introduced a four-year BSc optometry program. Unlike the Postgraduate Diploma, applicants to the BSc program were required to possess the senior secondary school certificate with aggregate score (grade point average) similar to that required to be admitted into the medical school in Ghana. The first set of 18 students was admitted into the BSc program in 2001. The program required 155 semester hours for graduation. In addition to the content of the post graduate diploma, courses were provided in areas such as low vision, contact lenses, ocular disease diagnosis and management, vision therapy, and clinical optometry. There was also emphasis on ocular diagnostic and therapeutic drugs as well as diagnosis and ocular disease management.

In the year 2004, KNUST phased out its BSc program and admitted its first set of Doctor of Optometry (OD) students at the beginning of the 2005/2006 academic year. The first batch of the BSc graduates was also readmitted to pursue the OD program. These 14 students became the first set of OD graduates trained in Ghana. They graduated with the OD degree in 2007 and were inducted in 2008 after completing a mandatory one year post graduation internship. Since KNUST eventually readmitted its BSc Optometry graduates to continue the OD program, no optometrist actually graduated with the BSc degree to practice in the country, except for a few who exited the program with the BSc and travelled outside the country for further studies.

\section{Optometric education at University of Cape Coast (UCC)}

The University of Cape Coast (UCC) is the third largest government funded University in Ghana. Established in October 1962, as a university college of education in special affiliation with the University of Ghana, it attained the status of a university in October 1971. In 2002, it established and admitted five students into its 6-year Doctor of Optometry (OD) program. Apparently, Dr Morny proposed the OD program to the authorities at UCC. Professor VPY Gadzekpo, then Dean of the Faculty of Science and Prof K Yankson, then Pro Vice chancellor, UCC were instrumental to the establishment of the optometry program in UCC. At the time, the University had decided to diversify the programs run at the University. Other programs that were established alongside the optometry program included Science Laboratory Technology and degree Nursing. The UCC program was initially designed as a combined bachelor of science in ophthalmic science and OD degree program. The four-year BSc (Ophthalmic science) was a nonterminal degree and candidates were expected to continue with the additional two-year clinical program for the award of the OD degree. The rationale for this arrangement was to allow those students who would like to exit the program after the first four year the opportunity to do so. At the time also, the optometry program at KNUST was a four-year BSc degree program. As though motivated by the UCC Doctor of Optometry program, KNUST commenced its OD program in 2004.

A total of 205 semester hours is required for graduation in the OD program at the University of Cape Coast $^{12}$. The program includes both didactic and clinical training that comprises visual sciences, physical and visual optics, clinical optometry, refraction, 
ocular disease diagnosis and treatment, low vision, pediatric optometry, contact lenses, public health and epidemiology as well as research methodology and orthoptics. Students undertake their clinical training at two on-campus clinics which serve the entire university community as well as the people from the Cape Coast Municipality. Additional clinical training is conducted at the Eye Department of the Central Regional Hospital and the Christian Eye Center both in Cape Coast. Long vacation ( 8 weeks) clinical postings to various eye departments across the country provided additional clinical exposure to the students as well as regular community outreach clinics.

Pioneering faculty for the UCC program included four Nigerian ODs namely Dr. FE Kio who was a visiting Senior Lecturer from the University of Benin; Dr Alex Illechie, Dr Godwin Ovenseri-Ogbomo and Dr Ukinebo Omoragbon who had trained at the University of Benin, Nigeria. Late Dr F K Morny, who was also instrumental to the setting up of the Optometry program in UCC, was also a member of the faculty (until 2006) commuting five hours by road from Kumasi. Other ancillary staffs from the department of human biology and sociology were also engaged. Optometry was the first health science program to be established in UCC. The program was established as a department. Professor Haruna Yakubu (from the Physics Department was appointed as the first Head of Department.

\section{Harmonization of optometric qualification}

Soon after the UCC program commenced and following the engagement of ODs from Nigeria, there became two cadres of optometrists in the country. These were optometrists with Post graduate diploma (PGDip) and Doctors of Optometry (OD). The presence of these two cadres of optometrists in the public service and academia portends some challenge for the advocacy effort to get the practice of optometry regulated. This is due in part to the fact that although the practice of optometry has occurred since 1950s, there is still very low awareness of optometric services among the general public and policy makers in Ghana.

Table 1: Comparison of the phases of optometric education in Ghana

\begin{tabular}{cccc}
\hline Admission & PG Dip & BSc & OD \\
Requirement & BSc in related science & SSSCE & SSSCE \\
Duration & 2 years & 4 years & 6 years \\
Scope & Primary care with & Primary care, contact & Addition to scope of \\
& emphasis on & lenses, binocular & BSc, ocular disease \\
& refraction & vision, Pediatric opt, & management, \\
& low vision and rehab, & diagnostic and \\
& diagnostic drugs & therapeutic drugs,
\end{tabular}


For example, while the entire optometry faculty in KNUST had the two-year post graduate diploma, the UCC Optometry faculty had OD and comparison between the two institutions was difficult. In order to address this challenge, KNUST entered into cooperative agreement and signed a memorandum of understanding with the University of Benin, Nigeria to jointly run an accelerated OD program for its faculty members. The arrangement provided for faculty from the University of Benin, Nigeria visiting KNUST to provide intensive didactic lectures and clinical instructions. At the completion of this linkage/upgrade, all KNUST faculty members were awarded the OD degree in 2008. Thus, currently, all KNUST optometry faculty members had a minimum professional qualification of the OD degree in addition to some post graduate qualification, such as Master in Public Health (MPH). In addition, a faculty member at KNUST holds a $\mathrm{PhD}$ from the US.

The next phase of the harmonization of optometric qualifications in Ghana was the introduction of a two year OD program at KNUST for the graduates of the PGDip program who are currently in practice in the country. The program which commenced in September 2010, is expected to be conducted on a modular basis for two years and will run until all the holders of the PGDip obtain their OD degrees.

\section{Optometry Licensure Examination}

To the best of our knowledge, currently, Ghana is the only African country where optometrists are required to seat and pass a licensing examination after successfully completing one year post-graduation internship at an eye care facility outside the university. The objectives of the licensing examination include: To assess the competencies of newly qualified ODs trained in the two schools of optometry,

To assess the competencies of ODs trained outside of Ghana who intends to practice in Ghana,

To keep up with practices in other health professions in developed countries, and

To raise the profile of the profession of optometry in Ghana.

The Ghana Optometric Association constituted the Optometry Examinations Board (OEB) with the responsibility of overseeing the conduct of the Optometry Licensure Examination. The OEB comprises two faculty members each from the two optometry departments and a senior practicing optometrist. The inaugural examination was conducted for the second set (the first set of ODs trained in Ghana had graduated and already engaged before the commencement of the licensure examination) of ODs trained in Ghana in November, 2009. Thirty eight candidates (33 from KNUST and five from UCC) took this inaugural examination and successful candidates were inducted into the profession and were given licenses to practice.

\section{Challenges}

Notwithstanding the modest progress in the development of optometric education in Ghana in the last 20 years, there have been a number of challenges. One major challenge that both programs have had to contend with is the fact that the programs started as a unit in the physics department. Thus at the beginning, the heads of the optometry programs were individuals who were not optometrists rather they were physicists or biologists and therefore, had difficulty running a programme that was new in the university, and which had an intensive clinical component. In the case of UCC, this was compounded by the fact that optometry was the first health professional programme in the university and therefore there was no antecedent to follow. Here the clinical component was quite daunting as the program was expected to run as other established programs in the university that had no clinical components. Not having optometrists as heads of the programme also meant that academic policies were made concerning the programs without adequate relevant professional inputs. It was also difficult to advocate for resources for these new programs. The low student intake for the programs meant that the program received little of the resources of the university which were distributed in proportion to student number. Poor infrastructure and lack of required textbooks also posed a huge challenge for these new programs. Recently, the UCC optometry program received some book donations from the Indiana University School of Optometry. The huge cost of optometric equipment has also militated against the necessary procurement of these equipments for training and research. The lack of equipment for research has limited research to basic epidemiological surveys with little basic opto- 
metric science research conducted in the two training programs.

The process of faculty development also presents a challenge. At the present, graduates from the top 5\% of the two programs are retained to train as academic faculty members. The lack of resources to sponsor these candidates to pursue graduate programmes both within and abroad, which will enhance the quality of teaching and research limits their individual potentials.

\section{Optometric education and legislation}

Although the need for the regulation of the practice of optometry in Ghana was the impetus for optometric education, two decades after the commencement of optometric education, the profession does not have any legal recognition. Several attempts at getting legal recognition by an Act of Parliament have not been successful. Despite the lack of legal recognition and regulation of the profession, optometrists are listed in the health workforce in the public service. For example, the placement of optometrists in the Ghana Health Service (GHS) took into account the length of training for an optometrist. The Ghana Optometric Association (GOA) also plays the role of a quasi-regulatory role by ensuring that optometrists in Ghana are registered with it. However, the constitutionally guaranteed freedom of association impedes the role of the GOA. This is because membership of the GOA is not mandatory and it is difficult for the Association to regulate the practice individuals who are not members of the Association.

\section{Conclusion}

Over the last 20 years, optometric education in Ghana has undergone three phases in its evolution: two-year Postgraduate Diploma (PGDip. Optom), four-year Bachelor of Science (BSc Optom) and a six-year Doctor of Optometry (OD) program. Initiatives are being taken to harmonize the minimum qualifications for the practice of optometry in the country. The advent of optometric education and the associated increase in the number of optometrists has not yet translated to the regulation of optometry practice yet in Ghana.

\section{References}

1. Penisten DK. Optometry and optometric education in Africa: past, present, and future. S Afr Optom 199251161 - 171.

2. Sheni DDD. The evolution of optometric education and practice in Africa. S Afr Optom 19985738 - 41.

3. Sheni DDD. The training of optometrists in West Africa. $S$ Afr Optom 19935261 - 63.

4. Ogbuehi PO. The development of optometric training in Nigeria. S Afr Optom 19935254 - 55.

5. Ferreira JT. The development and practice of optometry in South Africa. S Afr Optom 19935256 - 60.

6. Oduntan AO. Thirty years of optometric education at Turfloop (1975-2005): A historical and educational overview. $S$ Afr Optom $2006 \mathbf{6 5} 34$ - 40.

7. Mashige KP. Optometric education at Westville: past, present and future. S Afr Optom 2010 69(1) 14 - 20.

8. Randall JW, Kumah DB. The emergence of University Optometric education in Ghana. Optom Edu 2004 29(3) 80 - 84.

9. Carlson AS. Optometry in Ethiopia. S Afr Optom 2008 67(1) $42-44$

10. Collin HB, Bleything WB. Transactions of the second world conference on optometric education III: Panel on Africa. Clin Exp Optom 1994 77(6) 275 - 280.

11. Department of Physics. Course structure for the 2-year postgraduate diploma in optometry (Dip. Opt) at the University of Science and Technology, Kumasi, Ghana. November 1994.

12. Department of Optometry. Course contents for the Doctor of Optometry Program at the University of Cape Coast, Ghana. January, 2002. 